\title{
Examination of Some Country made Smooth Bore Firearms
}

Ajitesh Pal $^{\star}$ and Hemanta Kumar Pratihari

Tripura State Forensic Science Laboratory, Agartala, India

${ }^{*}$ Corresponding author: Ajitesh Pal, Tripura State Forensic Science Laboratory, Agartala-799015, India, E-mail: ajiteshp@rediffmail.com

Citation: Ajitesh Pal, Hemanta Kumar Pratihari (2014) Examination of Some Country made Smooth Bore Firearms. J Forensic sci criminol 2(5): 501. doi: 10.15744/2348-9804.2.101

Received Date: September 10, 2014 Accepted Date: October 21, 2014 Published Date: October 23, 2014

\begin{abstract}
Present trend of the crimes in India reveals that a wide variety of firearms including factory /country made are illegally used in crimes like murder, armed robbery, riot, poaching etc. Out of the total firearms received in Tripura State Forensic Science Laboratory, Agartala for the last ten years, about $30 \%$ of the firearms are observed to be belonging to country made pistol/pipe guns. On analysis of such firearms, it is observed that each firearm is unique in their design, loading and cocking mechanism. Such firearms are also different from standard one and sufficient literature is not available on them, hence it is necessary to make more research in this field. In this paper, some country made/improvised guns of 12 bore along with their ammunition received in different crime cases have been examined showing their action mechanism and other physical features. Further, the country made firearms studied in this paper are found so designed to chamber similar type of ammunition in them. The data on such firearms would be useful for the firearm experts and different law enforcement agencies to understand their action mechanism and lethality. Some points on preventive measures have also been suggested for eradicating illicit production/trafficking of such firearms.
\end{abstract}

Keywords: Country made pistol; Pipe gun; Ammunition; Action mechanism

\section{Introduction}

Analysis of case to case study in the laboratory and annual report of National Crime Records Bureau (NCRB), New Delhi, MHA, Govt. of India indicate that use of firearms particularly country made firearms are in increasing order in comparison to factory made firearms $[1,2]$. Such firearms are mostly seized from criminals, armed dacoits, terrorist, antisocial elements and poachers in different criminal activities. The making of such firearms is reported to be manufactured in commercial scale in many parts of India and become a cottage industry. Taking advantage of easy availability of such firearms at low cost, the criminals use to procure them for antisocial activities. In India persons are not allowed to possess firearms without police verification of antecedents likewise ammunition without license. In most of the cases, the criminals are found to procure such firearms and ammunition by illegal ways. Since the cost of factory made firearms are very high and to get the license is difficult, the criminals prefer to purchase country made firearms in clandestine way, hence the trade is flourishing in the country. The bullet/projectile fired from smooth bore country made firearms and subsequently recovered from the injured/deceased body are devoid of characteristic rifling marks, hence furnishing of definite opinion about the origin of projectile is very difficult for the forensic expert. Further, the use of nonstandard smooth bore country made firearms made of scarp materials is easily disposed of just after the commission of crime to escape detection. Very few studies are available in the literature on the mechanism and features of country made firearm [3-9]. The country made pistols and pipe guns examined in this paper are crudely made from scrap materials endangering human life. The ammunition used in such firearms are mostly factory made collected adopting various illegal ways by the antisocial. The aim of the present study is to explore the characteristic features, such as design, dimension, working mechanism, materials used in their making and ammunition fitted in such illegal firearms. This study will be useful reference for the ballistics expert and police in the interpretation of their findings in the court of law.

\section{Materials and Method}

A cross sectional descriptive study has been carried out on 62 number of country made pistols/pipe guns seized from different districts of the state Tripura by Police being the investigating agency. These firearms were examined in the laboratory from July, 2004 to August, 2014. All the country made/improvised firearms examined in the paper are categorized into four types such as (i) country made pistol, (ii) country made gun, (iii) improvised gun and (iv) country made pipe gun. Their photographs are shown in the Figures 1 to 4 and specifications are summarized in the Tables 1 to 4 showing the peculiarities and features. The common ammunition which could be used through all of the firearms described above are also shown in Figure 5 and their specification in the Table 5. Out of 62 firearms, 27 are breech loading pistols, 12 are breech loading country made guns, 7 are improvised breech loading guns and the rest are pipe guns. The barrels of such firearms are routinely checked by Borescope (KARL STORZ, Germany) to ascertain the presence of ammunition and defects if any before test firing. Their barrel length, overall length, breech diameter and muzzle diameter are measured with an electronic venire caliper (Mitutoyo, Japan). The weight is taken with a compact digital balance (National weighing and Instruments Company, Australia, Model FEJ-5000B) and trigger pull are measured with a spring balance (TAJ India Company). 


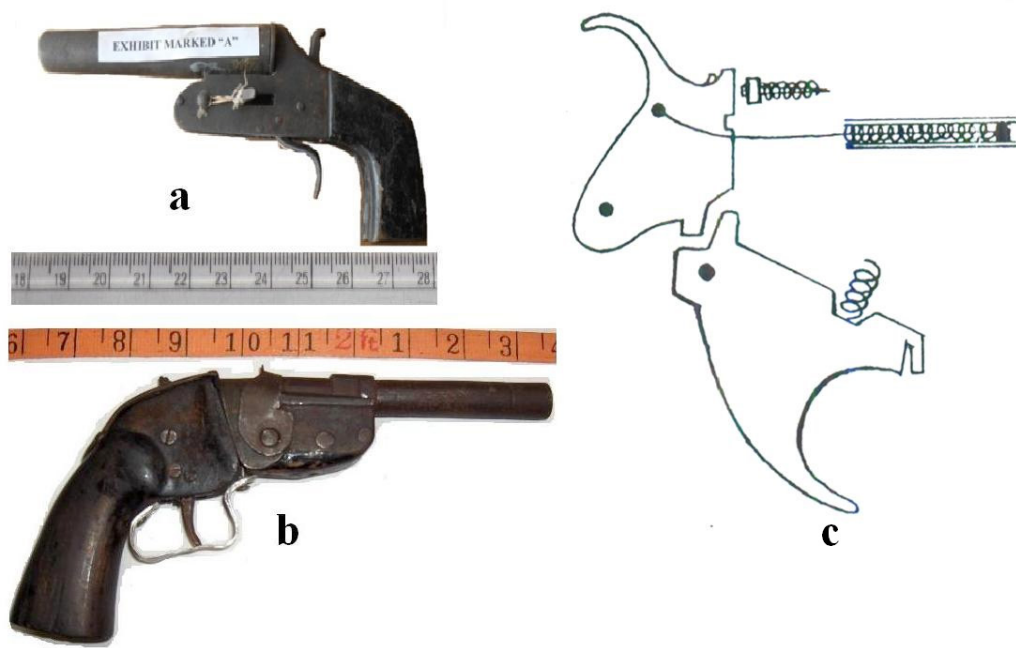

Figure 1: Two breech loading country made (CM) pistols (a, b) and their action mechanism(c)

\begin{tabular}{|c|c|c|}
\hline Parameters & Data on country made $(\mathbf{C M})$ pistol-a & Data on country made (CM) pistol-b \\
\hline Overall length $(\mathrm{cm})$ & 26 & 45.4 \\
\hline Barrel length $(\mathrm{cm})$ & 14.6 & 12.5 \\
\hline Muzzle diameter $(\mathrm{cm})$ & 1.75 & 1.7 \\
\hline Breech diameter $(\mathrm{cm})$ & 2.09 & 2.05 \\
\hline Weight $(\mathrm{g})$ & 732 & 370 \\
\hline Bore & 12 & 12 \\
\hline Rifling & Absent & Absent \\
\hline Capacity of Chamber & one & one \\
\hline Trigger Pull $($ Kg-wt) & 3 & 3.2 \\
\hline Action & Hammered & Hammered \\
\hline Cartridge & 12 bore cartridge & Single shot \\
\hline Firing characteristics & Single shot & bortridge \\
\hline
\end{tabular}

Table 1: Specification of the two firearms of Figure 1

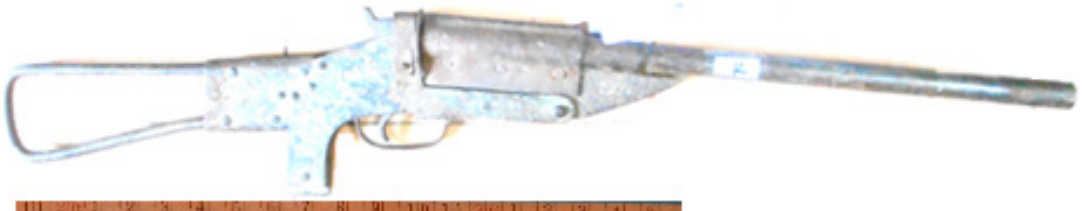

Figure 2: One breech loading country made (CM) gun

\begin{tabular}{|c|c|}
\hline Parameters & Data \\
\hline Overall length $(\mathrm{cm})$ & 86 \\
\hline Barrel length $(\mathrm{cm})$ & 50 \\
\hline Muzzle diameter $(\mathrm{cm})$ & 1.64 \\
\hline Breech diameter $(\mathrm{cm})$ & 2.1 \\
\hline Weight $(\mathrm{g})$ & 2.3 \\
\hline Bore & 12 \\
\hline Rifling & Absent \\
\hline Capacity of Chamber & One \\
\hline Trigger Pull $($ Kg-wt $)$ & 2 \\
\hline Action & Hammered \\
\hline Cartridge & 12 bore cartridge \\
\hline Firing characteristics & Single shot \\
\hline
\end{tabular}

Table 2: Specification of the firearm of Figure 2 


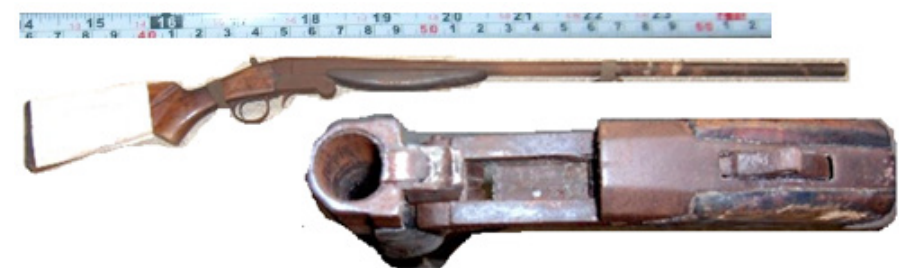

Figure 3: One breech loading improvised gun along with the enlarged view of its barrel

\begin{tabular}{|c|c|}
\hline Parameters & Data on the improvised gun \\
\hline Overall length $(\mathrm{cm})$ & 121.2 \\
\hline Barrel length $(\mathrm{cm})$ & 82.1 \\
\hline Muzzle diameter $(\mathrm{cm})$ & 1.78 \\
\hline Breech diameter $(\mathrm{cm})$ & 2.07 \\
\hline Weight $(\mathrm{g})$ & 2582 \\
\hline Bore & 12 \\
\hline Rifling & Absent \\
\hline Capacity of Chamber & one \\
\hline Trigger Pull $($ Kg-wt $)$ & 3.5 \\
\hline Action & Hammered \\
\hline Cartridge & 12 bore cartridge \\
\hline Firing characteristics & Single shot \\
\hline
\end{tabular}

Table 3: Specification of the firearm of Figure 3
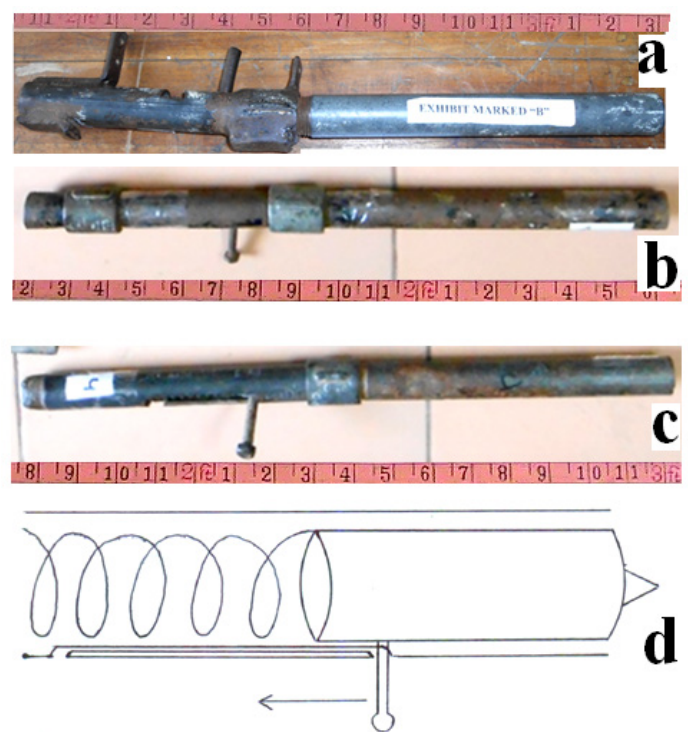

Figure 4: Three breech loading country made (CM) pipe guns (a, b, c) and their action mechanism (d)

\begin{tabular}{|c|c|c|c|}
\hline Parameters & Data on pipe gun-a & Data on pipe gun -b & Data on pipe gun -c \\
\hline Overall length $(\mathrm{cm})$ & 39.5 & 46 & 45 \\
\hline Barrel length $(\mathrm{cm})$ & 21.5 & 24.5 & 22 \\
\hline Muzzle diameter $(\mathrm{cm})$ & 2.12 & 2.16 & 2.07 \\
\hline Breech diameter $(\mathrm{cm})$ & 2.12 & 2.4 & 2.45 \\
\hline Weight $(\mathrm{g})$ & 870 & 904 & 998 \\
\hline Bore & 12 & 12 & Absent \\
\hline Rifling & Absent & Absent & One \\
\hline Capacity of Chamber & One & One \\
\hline Action & \multicolumn{3}{|c}{ Hammered } \\
\hline Cartridge & \multicolumn{3}{|}{ Single shot } \\
\hline Firing characteristics & \multicolumn{3}{|}{} \\
\hline \multicolumn{2}{|c}{}
\end{tabular}

Table 4: Specification of three firearms of Figure 4 


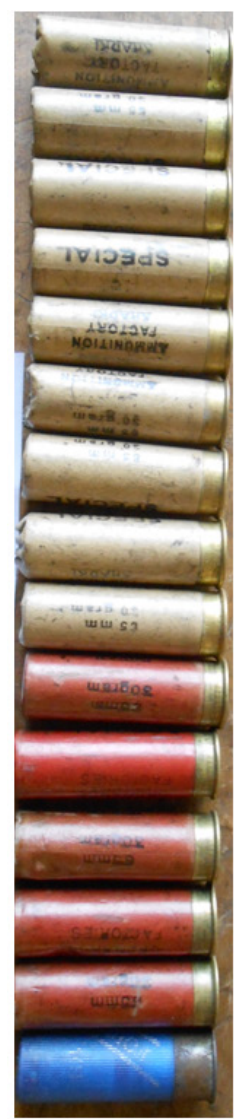

a

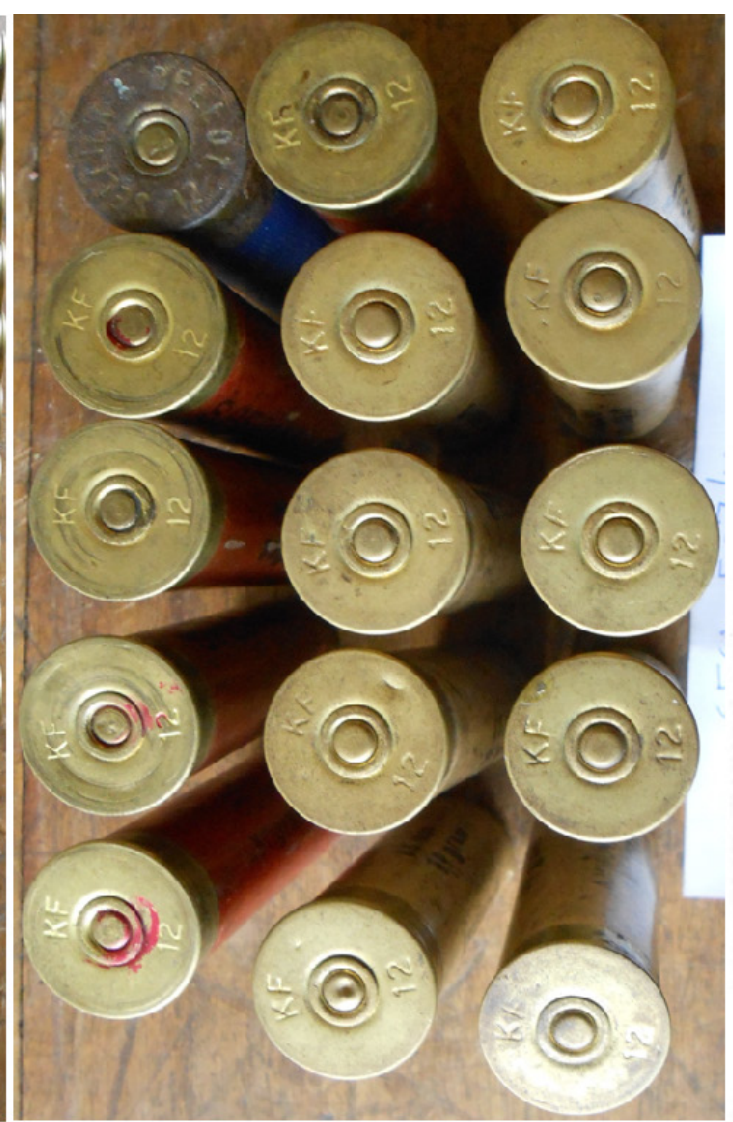

b

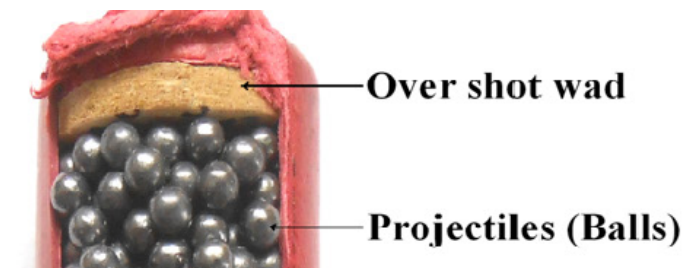

Cartridge case

(paper packet)

Under shot wad

Cushion wad

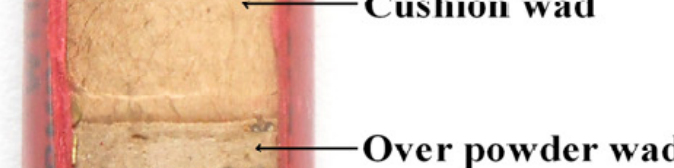

Powder charge

Base wad

Brass base

C

Figure 5: 12 bore ammunition (a), their head stamp (b) and sectioned view showing its different components (c)

\begin{tabular}{|c|c|}
\hline Parameters & Data \\
\hline Bore & 12 \\
\hline $\begin{array}{c}\text { Average diameter of the } \\
\text { base of ammunition }(\mathrm{mm}\end{array}$ & 20.28 \\
\hline Average weight $(\mathrm{g})$ & 48 to 50 \\
\hline Cartridge length $(\mathrm{cm})$ & 6.4 to 6.6 \\
\hline Total mass of the projectiles $(\mathrm{g})$ & 30 to 32 \\
\hline Mass of each projectile $($ ball $)(\mathrm{g})$ & 1.03 to 1.1 \\
\hline Type of propellant & Smokeless \\
\hline
\end{tabular}

Table 5: Specification of the ammunition of Figure 5

\section{Results and Discussion}

The country made firearms are made in small sweatshops and ordinary blacksmith having smattering knowledge can make and design such firearm unique by itself. The common features observed in all the four types of firearms are:

(i) The firearms are breech loading

(ii) They have same bore number and 12 bore cartridges are accommodated for use.

(iii) Their mechanism is based mainly on spring and trigger.

(iv) All the firearms have smooth bore and devoid of rifling marks inside the barrel.

(v) They have single barrel.

(vi) There is no provision of magazine in such firearm.

The country made firearms are generally made from crude materials such as steel or iron tubes, water pipes, screws, discarded steel or iron materials of automobiles, etc [3-5]. The wooden block is often used for making the stock of such firearms. 
Some firearm experts have studied various types of country made/improvised firearms such as pistol, revolver, pipe gun and shot gun seized in different crime cases [4-9]. Waghmare et al. [4] studied some smooth bore improvised .315 inch calibre and 12 bore pistols. Jain et al. [5] also reported some country made pistols which were capable to chamber and fire .315 and .303 inch rifle cartridges and some can fire 12 bore shotgun cartridges. The 12 bore guns were made of water pipe and their grips were covered with wooden piece.

The firearms shown in the Figures 1,2 and 3 are single action where the hammer is manually cocked with the thumb of the firing hand before each shot. This action set the pointed metallic piece used as firing pin in the same line with the centre of the base of the chambered cartridge inside the barrel. On pulling, the trigger releases the hammer to fire the cartridge through the barrel. In order to repeat the shot, the hammer is manually cocked again. The cocking of hammer usually acts as safety measure in such firearms. Compared to other auto loading handguns, these types of firearms are much simpler and easy to operate due to lighter and shorter trigger pull. The 12 bore breech loading country made/improvised guns studied in this paper are different not only from the 12 bore standard factory made firearms, but also differ from one another in design and action mechanism.

The three pipe guns shown in the Figure 4 are peculiar country made pipe guns which are very easy to make. In such firearms the cartridge is inserted into the barrel keeping the trigger in cocked position. When the trigger is released, it moves forward and the firing pin strikes the centre of the base of cartridge resulting firing. The pipe guns described here are different in cocking mechanism and shows peculiar design. One drawback of the firearms describe above is that the barrels made by cheap iron pipes are unsafe and risky for users.

It is evident from the Tables 1 to 4 that there are a lot of variations in the parameters of the examined firearms such as barrel length, muzzle diameter, thickness of the barrel wall, roughness of the inner surface of the barrel and trigger pull. Due to such variation, their range and wounding power are not same [10] even similar 12 bore ammunition are fired through all of them. The loose joints and non-standard barrels are responsible for their varying ballistics performance in comparison to the standard firearms.

The ammunition used in all the four types of firearms are 12 bore cartridges as shown in Figures 5 (a) and (b). The different components of one of these cartridges are also shown in the Figure 5 (c). It consists of thick paper /plastic packet in which powder charge and projectiles (spherical balls) are kept in compressed form using different wads such as base wad, over-powder wad, cushion wad, under shot wad, over-shot wad [10]. The wads are normally made of good quality cardboard and their diameter is slightly larger than the bore of the firearm. On firing these wads seal the barrel of the firearm and thus prevent escape of gases to avoid loss of velocity of the projectiles. The projectiles (balls) of the 12 bore cartridges examined are of same caliber and same mass with a very little variation. The 12 bore cartridge bears good capacity to hit at close range and also has good impact on the target due to use of hard metallic shots in them. Further, such ammunition is used by the criminals to eliminate the possibility of misfire and to achieve higher accuracy in firing due to the spreading pattern of shots. The spreading pattern of 12 bore cartridges may vary from firearm to firearm due to change in barrel length, muzzle diameter and trigger pull.

\section{Conclusion}

The examination of different breech loading country made firearms reveals the recent trend of design and action mechanism used in the making of country made pistols and pipe guns. It is noticed that the skilled gun-smith used to adopt sophisticated technique to develop the quality of firearms. All the different firearms studied in the paper are designed skillfully to fit similar ammunition. In spite of best expertise used to make country made firearms, but always their quality are found to be inferior to factory made firearms. The photographs and data on different country made firearms along with their action mechanism will help to build a good data bank for future reference and record. Further, the information about country made/improvised firearms and their database will be useful to firearm expert, police officers, judicial officers, law enforcement agencies and medico legal experts around the world. In order to eradicate illicit country made pistols/pipe guns, the following action plans are recommended by way of suggestion:

i. Possible sources of manufacturing illicit firearms and trafficking route are to be identified through intelligence feedback

ii. Stringent exemplary punishment to the king-pin of such illicit trade and person in possession/use

iii. Regular check/frisking at suspicious places by police

iv. Stricter gun control law

v. Providing alternative trade by way of financial assistance to the illicit gun manufacturer

\section{Acknowledgement}

The authors wish to thank Dr. M.S. Rao, Ex-Chief Forensic Scientist, MHA, Govt. of India, New Delhi for his support and encouragement. Authors also thank Dr. Sabyasachi Nath and Mr. Rajib Majumder for their assistance. 


\section{References}

1. Thejaswi HT, Kumar A, Jegadheeshwaraj (2013) Desi-Kutta (country made Firearm) and Wound Ballistics A Review. J Indian Acad Forensic Med 35: 165-9.

2. Crime in India 2011 Statistics (2011) NCRB, Ministry of Home Affairs, Chapter 3, Violent Crimes, 340.

3. Pal A, Pratihari HK (Summer 2014) Examination of some Indian homemade/improvised firearms and their ammunition. AFTE Journal 46: $234-7$.

4. Waghmare NP, Suresh R, Puri P, Varshney KC, Anand V, et al. (2012) Modern Trend of Country Made /Improvised Pistols Used in the Capital of India. J Forensic Res S1: 1-7.

5. Jain SK, Singh BP, Singh RP (2004) Indian homemade firearm-a technical review. Forensic Sci. Int. 144: 11-8.

6. Modi JK, Nigam C, Kumar K (1984) Improvised Firearms versus regular firearms. Forensic Sci Int 26: 199-205.

7. Warlow TA (2007) The Criminal use of improvised and re-activated firearms in Great Britain Northern Ireland. Sci Justice 47:111-9.

8. Mendis M (1997) Sri Lankan shot pistols and Ballistics. Sri Lankan Sci Justice 37: 259-63.

9. Bulent Uner H, Gokdagan MR, Cakan H (2003) Some samples of weapons and instruments used as weapon in criminal offences in Turkey. Forensic Sci Int 132: 113-6.

10. Sharma BR (2002) Firearms in Criminal Investigation and Trials. (3 ${ }^{\text {rd }}$ Edition), Universal Law Publishing Co. Pvt. Ltd., New Delhi, India.

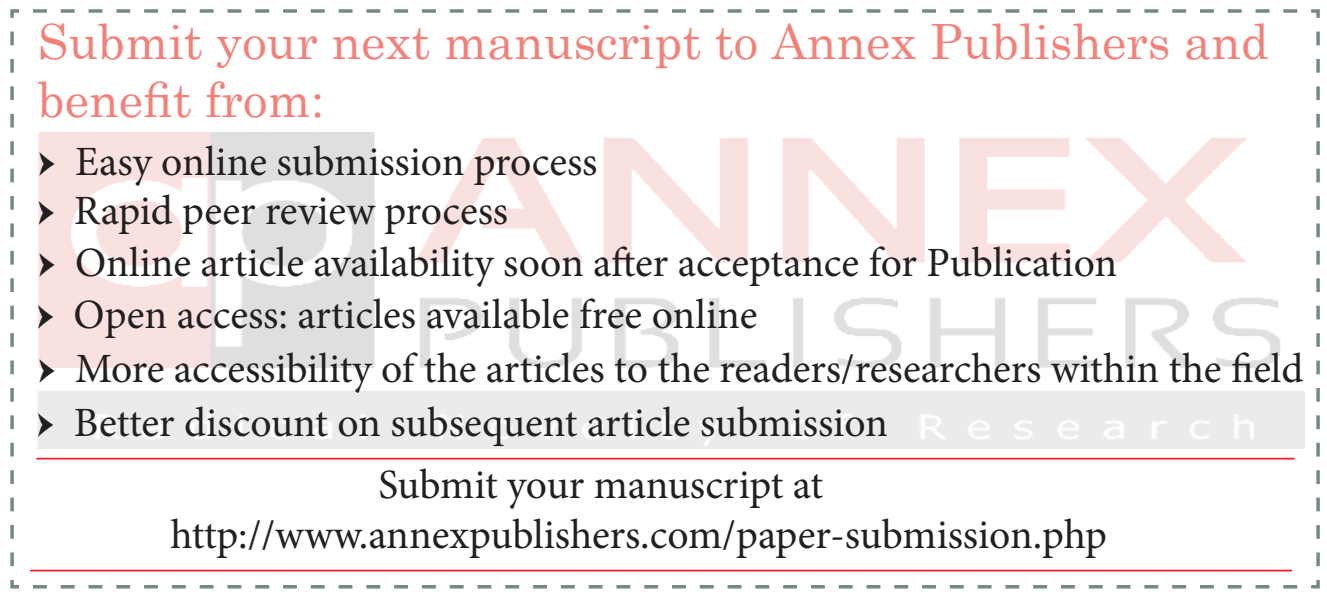

